\title{
The treatment of migraine patients within chiropractic: analysis of a nationally representative survey of 1869 chiropractors
}

\author{
Craig Moore $^{1 *}$, Jon Adams ${ }^{1}$, Andrew Leaver ${ }^{2}$, Romy Lauche ${ }^{1}$ and David Sibbritt ${ }^{1}$
}

\begin{abstract}
Background: While the clinical role of manual therapies in migraine management is unclear, the use of chiropractors for this condition is considerable. The aim of this study is to evaluate the prevalence and characteristics of chiropractors who frequently manage patients with migraine.

Methods: A national cross-sectional survey of chiropractors collected information on practitioner characteristics, clinical management characteristics and practice settings. A secondary analysis was conducted on 1869 respondents who reported on their migraine caseload to determine the predictors associated with the frequent management of patients with migraine.

Results: A large proportion of chiropractors report having a high migraine caseload (HMC) $(n=990 ; 53.0 \%)$. The strongest factors predicting a chiropractor having a HMC include the frequent treatment of patients with axial neck pain ( $\mathrm{OR}=2.89 ; 95 \% \mathrm{Cl}: 1.18,7.07)$, thoracic pain (referred/radicular) $(\mathrm{OR}=2.52 ; 95 \% \mathrm{Cl}: 1.58,3.21)$ and non-musculoskeletal disorders ( $\mathrm{OR}=3.06 ; 95 \% \mathrm{Cl}$ : 2.13, 4.39).

Conclusions: Several practice-setting and clinical management characteristics are associated with chiropractors managing a HMC. These findings raise key questions about the therapeutic approach to chiropractic migraine management that deserves further examination. There is a need for more primary research to assess the approach to headache and migraine management provided by chiropractors and to understand the prevalence, burden and comorbidities associated with migraine found within chiropractic patient populations. This information is vital in helping to inform safe, effective and coordinated care for migraine sufferers within the wider health system.
\end{abstract}

Keywords: Chiropractic, Migraine, Headaches, Practice-based research network, Utilisation, Manual therapy, Prevalence

\section{Background}

Migraine is the seventh leading cause of years lived with disability (YLDs) and a common neurological disorder [1]. During an attack, migraine symptoms are characterised by severe, throbbing, unilateral headaches associated with nausea, vomiting, photophobia and/or phonophobia and aggravation from physical activity and while less common, a migraine with aura is further associated with visual, sensory or speech related symptoms [2]. A variety of precipitating factors have been associated with triggering a

\footnotetext{
* Correspondence: craigsmoore@mac.com

${ }^{1}$ Australian Research Centre in Complementary and Integrative Medicine (ARCCIM), University of Technology Sydney, Level 8, Building 10, 235-253 Jones Street, Ultimo, NSW 2007, Australia

Full list of author information is available at the end of the article
}

migraine attack. Triggers reported include weather, stress, poor or over-sleeping, odours, missing meals and certain foods, menses and neck pain $[3,4]$.

Uncertainty remains regarding the mechanisms associated with the initiation of migraine pain. Evidence suggests migraine pain has a central origin involving the cortex and brainstem [5, 6]. Indirect evidence also suggests migraine pain has a peripheral origin whereby peripheral input from within cervical spine structures causes sensitization of trigeminal nociceptive pathways [7-9]. This may be more common in sufferers with neck pain and may involve convergent nociceptive input via the trigeminal nerve and the upper cervical afferents to the trigeminal cervical complex [10-12]. Interpretation of this indirect evidence may have implications for the role of manual therapies in the 
treatment of migraine [13, 14]. To date however, clinical trials to support the effectiveness of manual therapies, including soft tissue therapies, spinal manipulation and spinal mobilisation, for the prevention of migraine remains limited, of poor quality and sometimes conflicting [15-17]. Despite this clinical uncertainty, physical therapies, which may include manual therapies, are reported as the most frequently used complementary and alternative therapies for the management of headaches worldwide [18].

Chiropractors are one of the most common complementary and alternative medicine (CAM) providers globally [19-21]. The use of chiropractic for the treatment of headaches appears to be substantial [22-24] with migraine likely to be one of the most common headache types chiropractors manage [25-27]. Consequently, there is a need to better understand how many chiropractors have a high migraine caseload and whether this is more common to a particular type of chiropractor. While the treatment of migraine by chiropractors may be substantial, no research to date has reported on how prevalent such treatment is within the profession or the features of those chiropractors who provide it. In response, this study aimed to investigate the proportion of Australian chiropractors with a high migraine caseload; and the practitioner characteristics, practice characteristics and clinical management factors associated with frequent management of patients with migraine by chiropractors.

\section{Methods}

The analyses presented in this paper were drawn from a questionnaire distributed during recruitment for a national practice-based research network (PBRN) titled the Australian Chiropractic Research Network (ACORN) project. This national project is independently designed and conducted by senior researchers at the Australian Research Centre in Complementary and Integrative Medicine (ARCCIM), University of Technology Sydney. The ACORN 21-item questionnaire examining practitioner, practice and clinical management characteristics was distributed to all registered chiropractors across Australia (approval \# 2014000027) [28]. The secondary analyses sub-study reported in this paper were undertaken following ethical approval from the Human Research Ethics Committee of the University of Technology Sydney (approval \# ETH16-0474).

\section{Recruitment and sample}

Recruitment for the ACORN PBRN occurred through a profession-wide recruitment strategy conducted from March through to June 2015. An invitation pack was distributed to all registered Australian chiropractors who were invited to both complete the baseline ACORN questionnaire and to consent to participate in the ACORN PBRN project. Distribution was via post (hard copy), email (survey link) and at several regional profession-based conferences and was also made available through the official ACORN website (SurveyGizmo $\left.^{\mathrm{Tm}}\right)$. The invitation pack was similarly redistributed with four reminders starting 4 weeks after the initial invitation [28].

A total of 2005 chiropractors (43\% of the 4684 Australian chiropractors registered at time of recruitment) completed the baseline ACORN practitioner questionnaire. Participants were generally representative of the wider profession with regards to a number of key indicators when compared to registered chiropractors identified by AHPRA (Australian Health Practitioner Regulation Agency) at the time of recruitment [29] including age $(p=0.065)$ and gender $(p=0.634)$. While the ACORN baseline sample is also generally representative of the wider chiropractic population regarding practice location, we found slight differences in terms of the distribution by location with the questionnaire sample slightly overrepresented by chiropractors from South Australia, the Australian Capital Territory, Tasmania and the Northern Territory $(p<0.01)[28]$.

\section{Instrument}

The ACORN questionnaire collected information across three key domains (see Additional file 1). The first was practitioner characteristics (age, gender, education, professional qualifications and memberships in professional associations, years in private practice and professional roles in education, research and other professional areas). The second domain was practice characteristics (average patient care hours, number of weekly patient visits, place, number and type of practice location(s), types of health professionals working in the chiropractor's practice location, professional referral relationships and use of diagnostic imaging and electronic records). The third domain was clinical management characteristics where all response categories were on a four-point Likert frequency scale ('never', 'rarely', 'sometimes' or 'often'). This domain was divided into five sub-sections including frequency with which chiropractors discuss listed aspects of health promotion in their care plans; treat patients presenting with a range of listed conditions; treat patient subgroups and utilise listed treatment methods and interventions.

\section{Statistical analyses}

Statistical analyses were conducted using statistical software Stata 13.1 and SPSS 22.0 on those chiropractors who provided an answer to the question on how often they treat patients with migraine $(n=1869 ; 93.2 \%$ of all questionnaire respondents). The dependent variable was the frequency of treatment of patients with migraine; 'never,' 'rarely', 'sometimes' or 'often', which was dichotomized into those who treat patients with migraine 'often' 
and those who treat patients with migraine 'less often' (represented by the 'never', 'rarely' and 'sometimes' responses). Data are presented as means and standard deviations, or absolute and relative frequencies.

The bivariate associations between all survey items and the outcome variables were firstly explored using Student's t-test or chi-square tests, where applicable. Independent predictors of frequency of treating patients with migraine were identified using multiple logistic regression analysis. ACORN survey items with associations from the bivariate analyses $(p \leq 0.25)$ were included in the regression model. A backward stepwise procedure employing a likelihood ratio test was chosen to determine the independent predictors of chiropractors who treat patients with migraine 'often'. Statistical significance was set at $p<0.05$. Odds ratios were reported with $95 \%$ confidence intervals.

\section{Results}

Of the 1869 chiropractors, $62 \%$ were male with a mean (SD) age of 42.1 (12.1) years and most had a Bachelor or Master's degree qualifications (96\%). Participants had worked for an average of 15.8 (11.3) years in practice and worked an average of 27.3 (12.6) patient care hours each week. The majority of chiropractors reported managing patients with migraine 'often' ( $n=990 ; 53.0 \%)$. Fewer participants reported managing patients with migraine 'sometimes' $(n=765 ; 40.9 \%)$ and only a small percentage reported managing patients with migraine 'rarely' $(n=106 ; 5.7 \%)$ or 'never' $(n=8 ; 0.4 \%)$.

Chiropractors with a high migraine caseload ('often' group) were more often older $(p=0.001)$, had more years in practice $(p<0.001)$, worked a greater number of patient-care hours per week $(p<0.001)$ and reported a greater number of patient visits per week $(p<0.001)$ than those chiropractors with a lower migraine caseload (Table 1). The practice setting of chiropractors with a high migraine caseload was more often rural $(p=0.017)$ and they less often shared their practice location with a GP $(p=0.046)$ or psychologist/counsellor $(p=0.043)$ while more often had a referral relationship with an occupational therapist $(p=0.016)$, podiatrist $(\mathrm{p}=0.016)$ and/or exercise physiologist $(p=0.031)$. Additionally, these chiropractors more often used imaging in their practice $(p<0.001)$ but less often had diagnostic ultrasound on site $(p=0.008)$ than those chiropractors with a lower migraine caseload (Table 2).

Table 3 displays the clinical management characteristics of chiropractors with a high migraine caseload. The clinical management plans of chiropractors with a high migraine caseload more often included advice on diet/nutrition $(p<0.001)$, smoking/drugs/alcohol $(p<0.001)$, physical activity $(p=0.005)$, occupational health and safety $(p<0.001)$, pain counselling $(p<0.001)$, nutritional supplements $(p<0.001)$ and medications (including for pain/inflammation) $(p<0.001)$ than those chiropractors who less often managed patients with migraine. In addition, those chiropractors with a high migraine caseload more often treated patients presenting with neck, thoracic and low back pain, upper and lower limb disorders, postural disorders, degenerative conditions (all $p<0.001$ ), non-musculoskeletal conditions $(p<0.001)$, other headache disorders (excluding migraine) including cervicogenic and tension type headaches $(p<0.001)$ and spine health maintenance/prevention

Table 1 Distribution of practitioner characteristics across frequency of practitioner treating patients with migraine

\begin{tabular}{|c|c|c|c|}
\hline \multirow[t]{2}{*}{ Characteristic } & \multicolumn{2}{|c|}{ Treat patients with migraine } & \multirow[b]{2}{*}{$p$-value } \\
\hline & $\begin{array}{l}\text { Never/rarely/ } \\
\text { sometimes } \\
(n=879)\end{array}$ & $\begin{array}{l}\text { Often } \\
(n=990)\end{array}$ & \\
\hline Age in years (mean $\pm s d$ ) & $41.3 \pm 11.7$ & $43.1 \pm 12.3$ & 0.001 \\
\hline \multicolumn{4}{|l|}{ Gender } \\
\hline male n (\%) & $531(60.7)$ & $624(63.4)$ & \multirow[t]{2}{*}{0.237} \\
\hline female n (\%) & $344(39.3)$ & $361(36.6)$ & \\
\hline \multicolumn{4}{|l|}{ Qualification n (\%) } \\
\hline Diploma n (\%) & $20(2.3)$ & $21(2.1)$ & \multirow[t]{6}{*}{0.718} \\
\hline Advanced diploma n (\%) & $6(0.7)$ & $8(0.8)$ & \\
\hline Bachelor n (\%) & $304(34.9)$ & $344(35.0)$ & \\
\hline Doctor of Chiropractic n (\%) & $245(28.1)$ & $296(30.1)$ & \\
\hline Masters n (\%) & $288(33.0)$ & $308(31.4)$ & \\
\hline PhD n (\%) & $9(1.0)$ & $5(0.5)$ & \\
\hline Years in practice (mean \pm sd) & $14.9 \pm 11.0$ & $16.8 \pm 11.6$ & $<0.001$ \\
\hline Patient care hours/week (mean $\pm s d$ ) & $26.0 \pm 11.2$ & $28.0 \pm 10.4$ & $<0.001$ \\
\hline Patient visits/week (mean \pm sd) & $78.1 \pm 53.8$ & $95.5 \pm 59.2$ & $<0.001$ \\
\hline
\end{tabular}


Table 2 Distribution of practice characteristics across frequency of practitioner treating patients with migraine

\begin{tabular}{|c|c|c|c|}
\hline \multirow[t]{2}{*}{ Characteristic } & \multicolumn{2}{|c|}{ Treat patients with migraine } & \multirow[t]{2}{*}{$p$-value } \\
\hline & $\begin{array}{l}\text { Never/rarely/ } \\
\text { sometimes } \\
(n=879)\end{array}$ & $\begin{array}{l}\text { Often } \\
(n=990)\end{array}$ & \\
\hline \multicolumn{4}{|l|}{ Location } \\
\hline Urban n (\%) & $685(79.6)$ & $727(74.9)$ & 0.017 \\
\hline One location only & $214(24.5)$ & $257(26.0)$ & 0.441 \\
\hline \multicolumn{4}{|c|}{ Other health professionals in practice location } \\
\hline General practitioner & $68(7.7)$ & $54(5.5)$ & 0.046 \\
\hline Podiatrist & $93(10.6)$ & $86(8.7)$ & 0.165 \\
\hline Medical specialist & $26(3.0)$ & $25(2.5)$ & 0.567 \\
\hline Physiotherapist & $85(9.7)$ & $91(9.2)$ & 0.724 \\
\hline Chiropractor & $504(57.3)$ & $595(60.1)$ & 0.226 \\
\hline Exercise physiologist & $56(6.4)$ & $69(7.0)$ & 0.605 \\
\hline Psychologist & $126(14.3)$ & $111(11.2)$ & 0.043 \\
\hline Occupational therapist & $17(1.9)$ & $31(3.1)$ & 0.102 \\
\hline \multicolumn{4}{|l|}{ Referral relationships } \\
\hline General practitioner & $483(54.9)$ & $581(58.7)$ & 0.103 \\
\hline Psychologist & $119(13.5)$ & $147(14.8)$ & 0.418 \\
\hline Physiotherapist & $259(29.5)$ & $329(33.2)$ & 0.080 \\
\hline Occupational therapist & $59(6.7)$ & $97(9.8)$ & 0.016 \\
\hline Podiatrist & $323(36.7)$ & $418(42.2)$ & 0.016 \\
\hline Medical specialist & $129(14.7)$ & $168(17.0)$ & 0.176 \\
\hline Exercise physiologist & $120(13.7)$ & $171(17.3)$ & 0.031 \\
\hline Using imaging at least often & $332(38.1)$ & $549(55.7)$ & $<0.001$ \\
\hline \multicolumn{4}{|l|}{ Having imaging on site } \\
\hline X-ray & $138(15.7)$ & $144(14.5)$ & 0.487 \\
\hline Magnetic resonance imaging (MRI) & $36(4.1)$ & $26(2.6)$ & 0.077 \\
\hline Surface electromyography (SEMG) & $30(3.4)$ & $50(5.1)$ & 0.081 \\
\hline Diagnostic ultrasound & $35(4.0)$ & $19(1.9)$ & 0.008 \\
\hline Thermography & $33(3.8)$ & $55(5.6)$ & 0.067 \\
\hline
\end{tabular}

$(p<0.001)$ than chiropractors with a lower migraine caseload. In addition, they were more likely to treat pregnant women $(p<0.001)$, athletes/sports people $(p<0.001)$, Aboriginal and Torres Strait Islander people (ATSI) $(p<0.012)$, patients with work injuries $(p<0.001)$ and traffic injuries $(p$ $<0.001)$, patients from non-English speaking ethnic groups $(p<0.035)$, people receiving post-surgical rehabilitation $(p$ $<0.001$ ), and younger and older patients (all $p<0.001$ ) than those chiropractors with a lower migraine caseload. The treatment techniques/methods more often used by chiropractors with a high migraine caseload were high velocity, low amplitude (HVLA) spinal manipulation ( $p=$ $0.023)$, drop-piece techniques $(p=0.015)$, sacro-occipital techniques $(p<0.001)$, instrument adjusting $(p=0.001)$, biophysics $(p=0.040)$, applied kinesiology $(p=0.001)$, functional neurology $(p<0.001)$, dry needling $(p=0.006)$, heat/cryotherapy $(p=0.002)$, orthotics $(p<0.001)$ and extremity joint manipulation methods $(p<0.001)$.

Logistic regression analysis identified a range of factors independently associated with the likelihood of a chiropractor having a high migraine caseload. These factors included the chiropractor often discussing medications with their patients (including for pain/inflammation) $(\mathrm{OR}=1.55 ; 95 \% \mathrm{CI}: 1.09,2.21)$, treating patients with neck pain (axial) $(\mathrm{OR}=2.89$; 95\%CI: 1.18, 7.07), neck pain (referred/radicular) $(\mathrm{OR}=1.88 ; 95 \% \mathrm{CI}$ : 1.28, 2.77), thoracic pain (referred/radicular) $(\mathrm{OR}=2.52 ; 95 \% \mathrm{CI}$ : $1.58,3.21)$, low back pain (referred/radicular) $(\mathrm{OR}=1.78$; 95\%CI: 1.11, 2.85), upper limb musculoskeletal disorders (shoulder, elbow, wrist, hand) $(\mathrm{OR}=1.67$; 95\%CI: 1.20 , 2.31 ), providing spinal health maintenance/prevention $(\mathrm{OR}=1.59 ; \quad 95 \% \mathrm{CI}: \quad 1.12, \quad 2.25)$, treating non- 
Table 3 Distribution of clinical management characteristics across frequency of practitioner treating patients with migraine

\begin{tabular}{|c|c|c|c|}
\hline \multirow[t]{2}{*}{ Characteristic } & \multicolumn{2}{|c|}{ Treat patients with migraine } & \multirow[t]{2}{*}{$p$-value } \\
\hline & $\begin{array}{l}\text { Never/rarely/ } \\
\text { sometimes } \\
(n=879)\end{array}$ & $\begin{array}{l}\text { Often } \\
(n=990)\end{array}$ & \\
\hline \multicolumn{4}{|l|}{ Care plan includes (discussed often) } \\
\hline Diet/nutrition & $379(43.2)$ & $565(57.4)$ & $<0.001$ \\
\hline Smoking/drugs/alcohol & $171(19.5)$ & $295(30.1)$ & $<0.001$ \\
\hline Physical activity/fitness & $724(82.8)$ & $861(87.5)$ & 0.005 \\
\hline Occupational health and safety & $325(37.4)$ & $439(44.8)$ & 0.001 \\
\hline Pain counselling & $175(20.2)$ & $285(29.3)$ & $<0.001$ \\
\hline Nutritional supplements & $261(29.8)$ & $435(44.1)$ & $<0.001$ \\
\hline Medications (including pain/inflammation) & $165(19.1)$ & $264(27.0)$ & $<0.001$ \\
\hline \multicolumn{4}{|l|}{ Conditions (treated often) } \\
\hline Neck pain: Axial & $780(88.8)$ & $967(97.8)$ & $<0.001$ \\
\hline Neck pain: Referred/radicular & $374(42.5)$ & $799(80.7)$ & $<0.001$ \\
\hline Thoracic pain: Axial & $654(74.8)$ & $922(93.4)$ & $<0.001$ \\
\hline Thoracic pain: Referred/radicular & $227(26.1)$ & $632(64.4)$ & $<0.001$ \\
\hline Low back pain: Axial & $793(90.5)$ & $968(98.2)$ & $<0.001$ \\
\hline Low back pain: Referred/radicular & $600(68.5)$ & $910(92.2)$ & $<0.001$ \\
\hline Lower limb musculoskeletal disorders & $395(45.0)$ & $729(73.8)$ & $<0.001$ \\
\hline Upper limb musculoskeletal disorders & $416(47.4)$ & $748(76.1)$ & $<0.001$ \\
\hline Postural disorders & $442(50.5)$ & $765(77.7)$ & $<0.001$ \\
\hline Degenerative spine conditions & $642(73.1)$ & $986(99.7)$ & $<0.001$ \\
\hline Headaches (tension, cervicogenic) & $642(73.0)$ & $986(100.0)$ & $<0.001$ \\
\hline \multicolumn{4}{|l|}{ Migraine disorders } \\
\hline Spine health maintenance/prevention & $529(60.3)$ & $834(84.8)$ & $<0.001$ \\
\hline Non-Musculoskeletal conditions & $106(16.8)$ & $306(41.2)$ & $<0.001$ \\
\hline \multicolumn{4}{|l|}{ Patient groups (treated often) } \\
\hline Child: $<4$ years & $198(22.7)$ & $362(36.8)$ & $<0.001$ \\
\hline $4-18$ years & $363(41.6)$ & $627(63.6)$ & $<0.001$ \\
\hline Older: $>65$ years & $574(65.8)$ & $794(80.6)$ & $<0.001$ \\
\hline Aboriginal and Torres Strait islander & $8(0.9)$ & $24(2.5)$ & 0.012 \\
\hline Pregnant women & $233(26.8)$ & $448(45.7)$ & $<0.001$ \\
\hline Athletes/sports people & $339(39.1)$ & $572(58.5)$ & $<0.001$ \\
\hline Work Injuries & $250(38.9)$ & $418(42.8)$ & $<0.001$ \\
\hline Traffic Injuries & $58(6.7)$ & $196(20.1)$ & $<0.001$ \\
\hline Post-Surgical Rehabilitation & $32(3.7)$ & $88(9.0)$ & $<0.001$ \\
\hline Non-English Speaking ethnic groups & $43(5.1)$ & $72(7.5)$ & 0.035 \\
\hline \multicolumn{4}{|l|}{ Techniques/methods (used often) } \\
\hline Drop-piece & $443(51.0)$ & $549(56.7)$ & 0.015 \\
\hline Pelvic blocking/sacro-occipital & $343(39.7)$ & $465(48.1)$ & $<0.001$ \\
\hline Instrument Adjusting & $420(48.4)$ & $545(56.0)$ & 0.001 \\
\hline Chiropractic Biophysics & $28(3.3)$ & $49(5.4)$ & 0.040 \\
\hline HVLA manipulation/mobilisation & $694(80.0)$ & $821(84.1)$ & 0.023 \\
\hline Applied kinesiology & $113(13.1)$ & $182(19.1)$ & 0.001 \\
\hline Flexion-Distraction & $65(7.6)$ & $81(8.5)$ & 0.472 \\
\hline
\end{tabular}


Table 3 Distribution of clinical management characteristics across frequency of practitioner treating patients with migraine (Continued)

\begin{tabular}{|c|c|c|c|}
\hline \multirow[t]{2}{*}{ Characteristic } & \multicolumn{2}{|c|}{ Treat patients with migraine } & \multirow[t]{2}{*}{$p$-value } \\
\hline & $\begin{array}{l}\text { Never/rarely/ } \\
\text { sometimes } \\
(n=879)\end{array}$ & $\begin{array}{l}\text { Often } \\
(n=990)\end{array}$ & \\
\hline Functional Neurology & $71(8.4)$ & $168(17.8)$ & $<0.001$ \\
\hline Extremity Manipulation & $443(50.9)$ & $648(66.5)$ & $<0.001$ \\
\hline \multicolumn{4}{|c|}{ Musculoskeletal Interventions (used often) } \\
\hline Dry Needle or acupuncture & $98(11.3)$ & $153(15.7)$ & 0.006 \\
\hline Soft tissue therapies & 57365.9 & $650(66.1)$ & 0.905 \\
\hline Electro-modalities & $71(8.6)$ & $103(10.6)$ & 0.147 \\
\hline Heat/cryotherapy & $118(13.7)$ & $184(18.9)$ & 0.002 \\
\hline Orthotics & $55(6.4)$ & $134(13.8)$ & $<0.001$ \\
\hline Exercise therapy/rehabilitation & $411(47.7)$ & $497(51.1)$ & 0.140 \\
\hline
\end{tabular}

musculoskeletal disorders $(\mathrm{OR}=3.06$; 95\%CI: 2.13, 4.39), treating athletes/sports people $(\mathrm{OR}=1.65 ; 95 \% \mathrm{CI}$ : 1.22 , 2.23), employing functional neurology methods in their patient management $(\mathrm{OR}=1.63$; 95\%CI: $1.02,2.61)$ and less often having a psychologist/counsellor located in the same practice as the chiropractor $(\mathrm{OR}=0.53$; 95\%CI: $0.34,0.86$ ) (Table 4).

\section{Discussion}

\section{Prevalence of migraine management}

Our study found a large proportion of Australian chiropractors report managing a high migraine caseload. This appears to support previous studies which have identified a high prevalence of headache in chiropractic patient populations $(4.6 \%-15.4 \%)[30-32]$ and a high prevalence of chiropractic use within the general migraine population $(10 \%-29 \%)[23,25,26,33]$. The high use of chiropractors by those with migraine would suggest these providers are likely to be addressing some of the healthcare needs of this population and raises several questions for further research enquiry.

For instance, there is a need to better understand all of the relevant patient management approaches included within chiropractic migraine management and whether these approaches vary from those reported in routine Australian chiropractic practice which favours spinal manipulation, soft tissue therapy and exercise prescription [34]. For instance, while management of public health and lifestyle factors, have been captured in recent chiropractic workforce data $[35,36]$ there has been no detailed examination on how these aspects of patient management are utilised in the management of migraine. For example, little is known about the role chiropractors play in patient education regarding migraine triggers associated with diet, fatigue and stress or improving headache-related coping skills and pain management. While more high quality research is still needed to assess the effectiveness of individual manual therapies for the treatment of migraine, understanding

Table 4 Logistic regression output for chiropractors that treat migraine often compared to never/rarely/sometimes

\begin{tabular}{llll}
\hline Factors & Odds Ratio & $95 \%$ C.I. & $p$-value \\
\hline Non-musculoskeletal disorders & 3.058 & $2.132,4.388$ & $<0.001$ \\
Neck pain (Axial) & 2.889 & $1.181,7.068$ & 0.020 \\
Thoracic pain (Referred/radicular) & 2.252 & $1.580,3.210$ & $<0.001$ \\
Neck pain (Referred/radicular) & 1.881 & $1.280,2.764$ & 0.001 \\
Low back pain (Referred/radicular) & 1.783 & $1.115,2.851$ & 0.016 \\
Upper limb Musculoskeletal disorders & 1.668 & $1.206,2.308$ & 0.002 \\
Athletes or Sports people & 1.653 & $1.225,2.231$ & 0.001 \\
Functional Neurology & 1.632 & $1.020,2.610$ & 0.041 \\
Spinal health maintenance/prevention & 1.586 & $1.116,2.252$ & 0.010 \\
Discussing medication (Including pain/inflammation) & 1.555 & $1.093,2.213$ & 0.014 \\
Psychologist/counsellor in same practice & 0.543 & $0.342,0.862$ & 0.010 \\
\hline
\end{tabular}


the use of these management approaches by chiropractors and their influence on migraine health outcomes, both individually and synergistically, may prove helpful in the design of future clinical trials that aim to assess the overall effectiveness of chiropractic migraine management. Chiropractic clinical trials have yet to incorporate any multimodal aspects of chiropractic care that may influence underlying migraine mechanisms and have been limited to the assessment of unimodal manual therapy interventions for which headache treatment guidelines report only weak evidence or level III recommendations [37, 38].

\section{Factors associated with high migraine caseload}

Our analyses did not identify any practitioner characteristics (practitioner age, gender or place of education) that were associated with a high migraine caseload, suggesting that a broad cross-section of the Australian chiropractors are frequently managing those with migraine. However, our research highlights several practice-setting and clinical management characteristics associated with chiropractors managing a high migraine caseload and which raise valuable questions about the therapeutic or philosophical approaches that may be common to chiropractic migraine management.

Our study found chiropractors with a high migraine caseload were associated with treating spine regions (cervical, thoracic and lumbar) including referred and radicular spine symptoms associated with noxious stimulation of nerve endings and direct nerve root compression respectively [39], as well as treating upper limb disorders. Previous studies report manual therapies, particularly manipulative therapies, to be the most common therapies utilised by chiropractors when treating the spine and upper limb [34, 40-43]. Spinal manipulation in particular is reported to be the most popular treatment modality utlised by Australian chiropractors [35] and the only therapeutic modality to be evaluated by the profession for the treatment of migraine [15]. While unclear from our findings directly, these associations may suggest a greater preference for the use of manual therapies when compared to the use of other therapies amongst chiropractors with a high migraine caseload. More research is needed to assess the use of other therapeutic approaches that may also fall within the scope of chiropractors in their management of migraine. This could include the use of relaxation methods, herbs, minerals, supplements and physical therapies as identified within non-pharmaceutical migraine treatment guidelines [37, 44-46]. More research is also needed to understand the clinical circumstances within which chiropractors decide to refer patients with migraine to other healthcare providers for management and treatment that is outside their scope of practice.
Our analyses identified chiropractors with a high migraine caseload as more likely to provide treatment of patients with non-musculoskeletal conditions. While migraine itself is classified as a neurological disorder, the classification of migraine as a non-musculoskeletal condition is less straight forward when considering evidence of an association with neck pain and the potential role of neck pain in migraine pathophysiology [10, 11, 47, 48]. However, the treatment of a number of nonmusculoskeletal conditions with manual therapies by chiropractors is controversial, $[49,50]$ not least because of the significant methodological limitations in related clinical trials [51, 52] and concerns raised about the lack of biological plausibility to support how manual therapies, such as spinal manipulative therapy (SMT), might influence the underlying pathophysiology of these conditions [53]. On the other hand, higher headache disability and chronicity is more common amongst those who seek complementary medicine including chiropractic $[23,54]$ and this is associated with greater levels of anxiety and depression $[55,56]$. With the interest by some chiropractors toward improving overall patient health, including mental and emotional well-being [35, 57, 58], more research is needed to understand whether the association with treatment of patients with nonmusculoskeletal conditions may relate to care that is aimed to assist in the management of common migraine comorbidities, such as anxiety and depression, or toward the management of non-musculoskeletal conditions unrelated to migraine.

Our study also found chiropractors with a high migraine caseload are associated with providing spinal health maintenance and prevention. While there is limited research to identify a universal evidence-based definition of chiropractic maintenance care $[59,60]$, the role of preventative care is well recognised within healthcare settings including for the prevention of migraine [61], which often presents as a chronic or recurring condition [62, 63]. As such, the need to help sufferers through ongoing support, advice or treatment may be clinically indicated under a prevention paradigm. While ongoing SMT may be a popular component of chiropractic prevention [64, 65], more research is needed to understand all of the therapeutic modalities and approaches utilised under this therapeutic paradigm. With few clinical trials having included sufficient long-term follow-up to assess the benefits of chiropractic spinal health maintenance and prevention, no robust conclusions can be yet made about the long-term outcomes associated with this approach to care both for the management of conditions associated with the spine or the effect this type of care may have on those with migraine.

Our analyses identified chiropractors with a high migraine caseload as more likely to not have a psychologist/ counsellor practicing at the same practice location. While 
psychologists can be a key healthcare provider for those with headache $[38,66,67]$ it may be difficult to explain why chiropractors with a high migraine caseload are less likely to practice alongside psychologists. Possible explanations may be the potential influence of existing incentives for greater collaboration and therefore proximity between psychologists and other healthcare providers [68] or the possibility that chiropractors who often manage migraine may have a more independent therapeutic approach to the management of psychological aspects of patient health [69] suggesting less proximity reflects less inter-disciplinary collaboration with psychologists when managing this patient population. Alternatively, this could simply reflect a more general trend for Australian psychologists to work in independent private practice settings [70].

The association with discussing medications (including for pain/inflammation) by chiropractors who often manage migraine raises valuable questions about the nature of these patient discussions. These discussions may reflect the practitioners aim to assist migraine patients to manage their health 'without the use of drugs or surgery', a defining therapeutic and philosophical approach to patient care encouraged by chiropractic political bodies $[71,72]$ promoting better health without an unnecessary dependence on medications. These discussions may also reflect patient's raising concerns or dissatisfaction with migraine medications, a finding that has been reported as a key predictor for the use of complementary medicine including chiropractic for this patient population $[73,74]$. As a result, discussing current and previous migraine medications may be more common place inside consultations with migraine patients. More research is needed to understand the nature of discussions regarding migraine medications and whether these discussions extend beyond the normal documentation of current and previous treatments for a presenting complaint as expected for registered chiropractors under regulatory guidelines [75].

\section{Limitations}

Our secondary analysis of the ACORN cross-sectional survey provides an opportunity to answer a number of questions and identify further pertinent questions for future enquiry regarding chiropractic migraine management. Drawing strong conclusions from our research may be limited due to our analysis being secondary and the quality and fit of existing data to our research. As such, it cannot be concluded that the associations drawn from this secondary analysis are unique to the management of migraine patients. Our findings rely on practitioners understanding the classification criteria for migraine headache and the retrospective recall of practitioners when answering the original ACORN questionnaire. The Likert categories provided in the ACORN questionnaire ('never,' 'rarely', 'sometimes', 'often') for the frequency of migraine management are also subject to practitioner interpretation of these terms. There would also be a risk of selection bias if the features of the practitioners responding to the ACORN survey are less than representative of the wider profession. While the associations reported from our secondary analysis of the ACORN cross-sectional survey are preliminary, the findings nevertheless are valuable in helping to generate hypotheses to further explore the management and effectiveness of headache and migraine management by chiropractors.

\section{Conclusions}

Migraine appears to be a significant component of chiropractic caseload. There is a need for more high-quality research to better understand how chiropractors manage this patient population and to understand the prevalence, burden and comorbidities associated with migraine patients who seek help from these providers. Such information is important in helping to inform safe, effective and coordinated care for migraine sufferers within the wider health system.

\section{Additional file}

Additional file 1: ACORN national survey questionnaire (PDF 78 kb)

\section{Abbreviations}

ACORN: Australian Chiropractic Research Network; ARCCIM: Australian Research Centre in Complementary and Integrative Medicine; ATSI: Aboriginal and Torres Strait Islander; HVLA: High Velocity Low Amplitude; MRI: Magnetic Resonance Imaging; PBRN: Practice-Based Research Network; SEMG: Surface Electromyography; SMT: Spinal Manipulative Therapy; YLDs: Years Lived with Disability

\section{Acknowledgements}

The authors would like to thank the Chiropractors' Association of Australia for their financial support for the ACORN PBRN. The research reported in this paper is the sole responsibility of the authors and reflects the independent ideas and scholarship of the authors alone. The authors wish to acknowledge and thank the Australian chiropractors who participated in this study.

\section{Funding \\ The ACORN project is funded by the Chiropractors' Association of Australia. The funding source had no influence in the design of the study and collection, analysis, and interpretation of data and in writing the manuscript. Craig Moore has received a PhD scholarship from the Chiropractors' Association of Australia however the scholarship does not fund work related to this paper.}

\section{Availability of data and materials}

The datasets generated during and/or analysed during the current study are available from the corresponding author on reasonable request.

\section{Authors' contributions}

Designed the study: JA, DS; Collected the data: JA, DS; Analyzed the data: RL, $\mathrm{CM}$; Interpreted the data: $\mathrm{CM}, \mathrm{JA}, \mathrm{DS}, \mathrm{AL}, \mathrm{RL}$; Wrote the first draft: $\mathrm{CM}$; Critically revised the manuscript, and approved the final version: CM, JA, DS, $\mathrm{AL}, \mathrm{RL}$. 


\section{Ethics approval and consent to participate}

The ACORN PBRN has been approved by the UTS Human Ethics Committee (approval \#2014000027). All participants provided written informed consent.

\section{Consent for publication}

Not applicable

\section{Competing interests}

The authors declare that they have no competing interests.

\section{Publisher's Note}

Springer Nature remains neutral with regard to jurisdictional claims in published maps and institutional affiliations.

\begin{abstract}
Author details
'Australian Research Centre in Complementary and Integrative Medicine (ARCCIM), University of Technology Sydney, Level 8, Building 10, 235-253 Jones Street, Ultimo, NSW 2007, Australia. ${ }^{2}$ Faculty of Health Science, University of Sydney, Sydney, Australia.
\end{abstract}

Received: 21 June 2017 Accepted: 22 November 2017

Published online: 04 December 2017

\section{References}

1. Vos T, Flaxman AD, Naghavi M, Lozano R, Michaud C, Ezzati M, Shibuya K, Salomon JA, Abdalla S, Aboyans V. Years lived with disability (YLDs) for 1160 sequelae of 289 diseases and injuries 1990-2010: a systematic analysis for the global burden of disease study 2010. Lancet. 2013;380:2163-96.

2. Headache Classification Committee of the International Headache S. The international classification of headache disorders, 3rd edition (beta version). Cephalalgia. 2013;33:629-808.

3. Andress-Rothrock D, King W, Rothrock J. An analysis of migraine triggers in a clinic-based population. Headache. 2010:50:1366-70.

4. Kelman $\mathrm{L}$. The triggers or precipitants of the acute migraine attack. Cephalalgia. 2007:27:394-402

5. Lambert GA. The lack of peripheral pathology in migraine headache. Headache. 2010:50:895-908.

6. Coppola G, Pierelli F, Schoenen J. Is the cerebral cortex hyperexcitable or hyperresponsive in migraine? Cephalalgia. 2007;27:1427-39.

7. Levy D. Migraine pain and Nociceptor activation-where do we stand? Headache. 2010;50:909-16.

8. Bartsch T. Migraine and the neck: new insights from basic data. Curr Pain Headache Rep. 2005;9:191-6.

9. Fernández-de-las-Peñas C, Madeleine $P$, Caminero A, Cuadrado M Arendt-Nielsen L, Pareja J. Generalized neck-shoulder hyperalgesia in chronic tension-type headache and unilateral migraine assessed by pressure pain sensitivity topographical maps of the trapezius muscle. Cephalalgia. 2009:30:77-86.

10. Florencio LL, Chaves TC, Carvalho GF, Gonçalves MC, Casimiro ECB, Dach F, Bigal ME, Bevilaqua-Grossi D. Neck pain disability is related to the frequency of migraine attacks: a cross-sectional study. Headache. 2014;54:1203-10.

11. Ashina S, Bendtsen L, Lyngberg AC, Lipton RB, Hajiyeva N, Jensen R. Prevalence of neck pain in migraine and tension-type headache: a population study. Cephalalgia. 2015;35:211-9.

12. Ford S, Calhoun A, Kahn K, Mann J, Finkel A. Predictors of disability in Migraineurs referred to a tertiary clinic: neck pain, headache characteristics, and coping behaviors. Headache. 2008:48:523-8.

13. Nijs J, Meeus M, Van Oosterwijck J, Roussel N, De Kooning M, Ickmans $K$, Matic M. Treatment of central sensitization in patients with 'unexplained' chronic pain: what options do we have? Expert Opin Pharmacother. 2011:12:1087-98.

14. Nijs J, Van Houdenhove B, Oostendorp RA. Recognition of central sensitization in patients with musculoskeletal pain: application of pain neurophysiology in manual therapy practice. Man Ther. 2010;15:135-41.

15. Chaibi A, Tuchin PJ, Russell MB. Manual therapies for migraine: a systematic review. J Headache Pain. 2011:12:127-33.

16. Posadzki P, Ernst E. Spinal manipulations for the treatment of migraine: a systematic review of randomized clinical trials. Cephalalgia. 2011:31:964-70.

17. Bryans R, Descarreaux M, Duranleau M, Marcoux H, Potter B, Ruegg R, Shaw L, Watkin R, White E. Evidence-based guidelines for the chiropractic treatment of adults with headache. J Manip Physiol Ther. 2011;34:274-89.
18. WHO Lifting the Burden.http://www.who.int/mental_health/management/ who atlas headache disorders.pdf?ua=1. Accessed 1 Nov 2017.

19. Zodet MW, Stevans JM. The 2008 prevalence of chiropractic use in the US adult population. J Manip Physiol Ther. 2012:35:580-8.

20. Thomas KJ, Nicholl JP, Coleman P. Use and expenditure on complementary medicine in England: a population based survey. Complement Ther Med. 2001;9:2-11.

21. Ong CK, Doll H, Bodeker G, Stewart-Brown S. Use of osteopathic or chiropractic services among people with back pain: a UK population survey Health \& social care in the community. 2004;12:265-73.

22. Brown B, Bonello R, Fernandez-Caamano R, Graham P, Eaton S, Green H. Chiropractic in Australia : a survey of the general public. Chiropractic journal of Australia. 2013:43:85-92.

23. Kristoffersen ES, Grande RB, Aaseth K, Lundqvist C, Russell MB. Management of primary chronic headache in the general population: the Akershus study of chronic headache. J Headache Pain. 2012;13:113-20.

24. Ossendorf A, Schulte E, Hermann K, Hagmeister H, Schenk M, Kopf A, Schuh-Hofer S, Willich SN, Berghöfer A. Use of complementary medicine in patients with chronic pain. Eur J Integr Med. 2009:1:93-8.

25. Wells RE, Bertisch SM, Buettner C, Phillips RS, McCarthy EP. Complementary and alternative medicine use among adults with migraines/severe headaches. Headache. 2011;51:1087-97.

26. Sanderson JC, Devine EB, Lipton RB, Bloudek LM, Varon SF, Blumenfeld AM, Goadsby PJ, Buse DC, Sullivan SD. Headache-related health resource utilisation in chronic and episodic migraine across six countries. J Neurol Neurosurg Psychiatry. 2013;84:1309-17.

27. Moore CS, Sibbritt DW, Adams J. A critical review of manual therapy use for headache disorders: prevalence, profiles, motivations, communication and self-reported effectiveness. BMC Neurol. 2017;17:1-11.

28. Adams J, Steel A, Moore C, Amorin-Woods L, Sibbritt D. Establishing the ACORN National Practitioner Database: strategies to recruit practitioners to a National Practice-Based Research Network. J Manip Physiol Ther. 2016;39:594-602.

29. Chiropractic registrant data. 2014. http://www.chiropracticboard.gov.au/ About-the-Board/Statistics.aspx. Accessed 1 Nov. 2017.

30. Rubinstein S, Pfeifle CE, Tulder MW, Assendelft WJ. Chiropractic patients in the Netherlands: a descriptive study. J Manip Physiol Ther. 2000;23:557-63.

31. Jackson P. Summary of the 2000 ACA professional survey on chiropractic practice. J Am Chiro Assn. 2001;38:27-30.

32. Brown BT, Bonello R, Fernandez-Caamano R, Eaton S, Graham PL, Green H. Consumer characteristics and perceptions of chiropractic and chiropractic Services in Australia: results from a cross-sectional survey. J Manip Physiol Ther. 2014:37:219-29.

33. Bigal ME, Serrano D, Reed M, Lipton RB. Chronic migraine in the population burden, diagnosis, and satisfaction with treatment. Neurology. 2008;71:559-66.

34. Clijsters M, Fronzoni F, Jenkins $H$. Chiropractic treatment approaches for spinal musculoskeletal conditions: a cross-sectional survey. Chiropr Man Therap. 2014:22:33.

35. Adams J, Lauche R, Peng W, Steel A, Moore C, Amorin-Woods LG, Sibbritt D. A workforce survey of Australian chiropractic: the profile and practice features of a nationally representative sample of 2,005 chiropractors. BMC Complement Altern Med. 2017:17:14

36. National Health Workforce Dataset (NHWDS) Chiropractic. 2015. http:// data.hwa.gov.au/webapi/customer/documents/factsheets/2015/ Chiropractic\%20-\%202015.pdf. Accessed 29 Nov 2017.

37. Sarchielli P, Granella F, Prudenzano M, Pini L, Guidetti V, Bono G, Pinessi L, Alessandri M, Antonaci F, Fanciullacci M, et al. Italian guidelines for primary headaches: 2012 revised version. J Headache Pain. 2012;13:31-70.

38. Campbell J, Penzien D, Wall E. Evidence-based guidelines for migraine headache: behavioral and physical treatments. US Headache Consortium. 2000;1:1-29.

39. Bogduk N. On the definitions and physiology of back pain, referred pain, and radicular pain. Pain. 2009;147:17-9.

40. Carlesso LC, MacDermid JC, Gross AR, Walton DM, Santaguida PL. Treatment preferences amongst physical therapists and chiropractors for the management of neck pain: results of an international survey. Chiropr Man Therap. 2014;22:11

41. Pribicevic M, Pollard $H$, Bonello $R$. An epidemiologic survey of shoulder pain in chiropractic practice in Australia. J Manip Physiol Ther. 2009;32:107-17.

42. van de Veen EA de Vet HCW, Pool JJM, Schuller W, de Zoete A, Bouter LM. Variance in manual treatment of nonspecific low back pain between 
Orthomanual physicians, manual therapists, and chiropractors. J Manip Physiol Ther. 2005;28:108-16.

43. McHardy A, Hoskins W, Pollard H, Onley R, Windsham R. Chiropractic treatment of upper extremity conditions: a systematic review. J Manip Physiol Ther. 2008;31:146-59.

44. Holland S, Silberstein SD, Freitag F, Dodick DW, Argoff C, Ashman E. Evidence-based guideline update: NSAIDs and other complementary treatments for episodic migraine prevention in adults. Neurology. 2012;78:1346-53

45. Pringsheim T, Davenport WJ, Mackie G, Worthington I, Aubé M, Christie SN, Gladstone J, Becker WJ. Canadian headache society guideline for migraine prophylaxis. Can J Neurol Sci. 2012;39:S1-S59.

46. Becker WJ, Findlay T, Moga C, Scott NA, Harstall C, Taenzer P. Guideline for primary care management of headache in adults. Can Fam Physician. 2015;61:670-9.

47. Calandre E, Hidalgo J, Garcia-Leiva J, RiceVillademoros F. Trigger point evaluation in migraine patients: an indication of peripheral sensitization linked to migraine predisposition? Eur J Neurol. 2006;13:244-9.

48. Fernández-de-las-Peñas C, Cuadrado M, Pareja J. Myofascial trigger points, neck mobility and forward head posture in unilateral migraine. Cephalalgia. 2006;26:1061-70

49. Harvey K. A critical appraisal of evidence and arguments used by Australian chiropractors to promote therapeutic interventions. Chiropr I Australia. 2016:44:234-45.

50. Ernst E, Gilbey A. Chiropractic claims in the English-speaking world. N Z Med J. 2010;123:36-44.

51. Ferrance RJ, Miller J. Chiropractic diagnosis and management of nonmusculoskeletal conditions in children and adolescents. Chiropr Osteopat. 2010;18:14.

52. Clar C, Tsertsvadze A, Court R, Hundt G, Clarke A, Sutcliffe P. Clinical effectiveness of manual therapy for the management of musculoskeletal and non-musculoskeletal conditions; systematic review and update of UK evidence report. Chiropr Man Therap. 2014;28:1.

53. Mirtz TA, Morgan L, Wyatt LH, Greene L. An epidemiological examination of the subluxation construct using Hill's criteria of causation. Chiropr Osteopat. 2009;17:13.

54. Minen MT, Seng EK, Holroyd KA. Influence of family psychiatric and headache history on migraine-related health care utilization. Headache. 2014:54:485-92

55. Lipton RB, Buse DC, Serrano D, Holland S, Reed ML. Examination of unmet treatment needs among persons with episodic migraine: results of the American migraine prevalence and prevention (AMPP) study. Headache. 2013:53:1300-11.

56. Lantéri-Minet M, Radat F, Chautard M-H, Lucas C. Anxiety and depression associated with migraine: influence on migraine subjects' disability and quality of life, and acute migraine management. Pain. 2005;118:319-26.

57. Dehen MD, Whalen WM, Farabaugh RJ, Hawk C. Consensus terminology for stages of care: acute, chronic, recurrent, and wellness. J Manip Physiol Ther. 2010;33:458-63.

58. Hawk C, Schneider M, Dougherty P, Gleberzon BJ, Killinger LZ. Best practices recommendations for chiropractic care for older adults: results of a consensus process. J Manip Physiol Ther. 2010;33:464-73.

59. Hawk C, Schneider M, Evans M, Redwood D. Consensus process to develop a best-practice document on the role of chiropractic Care in Health Promotion, disease prevention, and wellness. J Manip Physiol Ther. 2012;35:556-67.

60. Leboeuf-Yde C, Hestbæk L. Maintenance care in chiropractic-what do we know? Chiropr Osteopat. 2008;16:1.

61. Serrano D, Manack AN, Reed ML, Buse DC, Varon SF, Lipton RB. Cost and predictors of lost productive time in chronic migraine and episodic migraine: results from the American migraine prevalence and prevention (AMPP) study. Value Health. 2013;16:31-8.

62. Lanteri-Minet M. Economic burden and costs of chronic migraine. Curr Pain Headache Rep. 2014;18:385.

63. Buse D, Manack A, Serrano D, Reed M, Varon S, Turkel C, Lipton R. Headache impact of chronic and episodic migraine: results from the American migraine prevalence and prevention study. Headache. 2012;52:3-17.

64. Rupert RL. A survey of practice patterns and the health promotion and prevention attitudes of US chiropractors. Maintenance care: part I. J Manip Physiol Ther. 2000;23:1-9.

65. Jamison JR, Rupert RL. Maintenance care: towards a global description. The Journal of the Canadian Chiropractic Association. 2001;45:100.
66. Lipchik GL, Smitherman TA, Penzien DB, Holroyd KA. Basic principles and techniques of cognitive-behavioral therapies for Comorbid psychiatric symptoms among headache patients. Headache. 2006;46:5119-32.

67. Smitherman TA, Maizels M, Penzien DB. Headache chronification: screening and behavioral management of comorbid depressive and anxiety disorders. Headache. 2008:48:45-50.

68. Better Access to Mental Healthcare. http//www.health.gov.au/internet/ publications/publishing.nsf/Content/mental-ba-eval-f-toc. Accessed 29 Nov 2017.

69. McDonald WP, Durkin KF, Pfefer M. How chiropractors think and practice: the survey of north American chiropractors. Seminars in Integrative Medicine. 2004;2:92-8.

70. Stokes D, Mathews R, Grenyer BFS, Crea K. The Australian psychology workforce 3: a national profile of psychologists in salaried employment or in independent private practice. Aust Psychol. 2010;45:178-88.

71. About the chiropractors association of Australia. http://www. chiropractorsnsw.asn.au/what-does-chiropractic-care-involve. Accessed 29 Nov 2017.

72. WFC quarterly world report. https://www.wfc.org/website/images/wfc/qwr/ QWR201303_NEW_final.pdf. Accessed 29 Nov 2017.

73. von Peter S, Ting W, Scrivani S, Korkin E, Okvat H, Gross M, Oz C, Balmaceda C. Survey on the use of complementary and alternative medicine among patients with headache syndromes. Cephalalgia. 2002;22:395-400.

74. Gaul C, Eismann R, Schmidt T, May A, Leinisch E, Wieser T, Evers S, Henkel K, Franz G, Zierz $\mathrm{S}$. Use of complementary and alternative medicine in patients suffering from primary headache disorders. Cephalalgia. 2009;29:1069-78.

75. Code of conduct for chiropractors. http://www.chiropracticboard.gov.au/ Codes-guidelines/Code-of-conduct.aspx. Accessed 29 Nov 2017.

\section{Submit your next manuscript to BioMed Central and we will help you at every step:}

- We accept pre-submission inquiries

- Our selector tool helps you to find the most relevant journal

- We provide round the clock customer support

- Convenient online submission

- Thorough peer review

- Inclusion in PubMed and all major indexing services

- Maximum visibility for your research

Submit your manuscript at www.biomedcentral.com/submit
) Biomed Central 